\title{
Piezoelectric Microfiber Composite Actuators for Morphing Wings
}

\author{
Timothy D. Usher, Kenneth R. Ulibarri Jr., and Gilberto S. Camargo \\ Department of Physics, California State University at San Bernardino, 5500 University Parkway, San Bernardino, CA 92407, USA \\ Correspondence should be addressed to Timothy D. Usher; tusher@csusb.edu
}

Received 27 November 2012; Accepted 22 December 2012

Academic Editors: I. Dubenko and K. Hokamoto

Copyright (c) 2013 Timothy D. Usher et al. This is an open access article distributed under the Creative Commons Attribution License, which permits unrestricted use, distribution, and reproduction in any medium, provided the original work is properly cited.

Morphing wing technologies provide expanded functionality in piloted and robotic aircraft, extending particular vehicle mission parameters as well as increasing the role of aviation in both military and civilian applications. However, realizing control surfaces that do not void the benefits of morphing wings presents challenges that can be addressed with microfiber composite actuators (MFCs). We present two approaches for realizing control surfaces. In one approach, flap-like structures are formed by bonding MFCs to each side of a metal substrate. In the other approach, MFCs are bonded directly to the wing. Counter intuitively, the flap approach resulted in larger voltage actuation curvatures, with increased mass load. Actuation performance, defined as the ratio of curvature per applied voltage, was as large as $5.8 \pm 0.2 \times 10^{-4}(\mathrm{kV} \cdot \mathrm{mm})^{-1}$. The direct bonding approach reveals that at zero wing pressure, up to $63 \pm 3 \mu \mathrm{m}$ of displacement could be realized.

\section{Introduction}

Traditional piezoelectric actuators, often referred to as "stack" actuators, have been used in numerous applications, including aeronautical applications $[1,2]$. Traditional piezoelectric actuators are typically capable of exerting high pressures, but with small strains. This has limited their applicability. Newer actuator designs overcome the limitations of small displacements typical of traditional piezoelectric actuators by trading the characteristic high pressures for larger displacements. This is usually accomplished through various composite structures rather than expensive, high precision micromachined leveraging designs. Some of these newer composite actuator designs include Moonies [3], Rainbow [4], THUNDER [5], LIPCA [6], ECLIPSE [7], and MFCs [8]. Although several actuators show promise in other applications, micro-robotics [9]; for example, MFCs were chosen for this application because they are more flexible. In addition, they have been used in other aeronautical applications $[10,11]$. A review of morphing aircraft can be found in [12].

The MFC actuators are formed by sandwiching piezoelectric fibers between polyimide layers. The polyimide layers have interdigitated electrodes that are a key feature of MFCs. They allow the utilization of the higher $\mathrm{d}_{33}$ piezoelectric coupling constants rather than the lower transverse $d_{31}$ coupling constant. The high dielectric constant of the piezoelectric fiber concentrates, or condenses, the applied electric field inside the ceramic. More detailed information about MFCs can be found in the literature $[8,13,14]$. In this study we focus on an important aeronautical application of MFC actuators, specifically, morphing wings.

Morphing wings exhibit significant advantages over fixed wing aircraft in many applications. In this investigation, we focus on an extreme example of morphing wing technology, inflatable wings, in particular, one developed by ILC Dover. Inflatable wings provide unique capabilities, for example, the ability to fold the deflated wings into a cylinder for quick deployment via conventional artillery or aerial drop assemblies $[15,16]$. Upon reaching the target area, the wings are deployed and the aircraft can loiter for long periods. However, one challenge is that of realizing control surfaces for these inflatable wings.

We present experimental results applicable to two alternate approaches for realizing control surfaces that incorporate MFCs. The first approach utilizes the MFC in 
a traditional flap configuration. This approach provided large DC displacements. Further optimization should result in the full range of displacements found in conventional flaps. In the second approach, successful procedures were developed for bonding MFC actuators directly to the surface of an inflatable wing. The experimental results show that the DC displacements are tension load limited, resulting in small displacements at higher wing pressures. However, modifications to this approach are suggested for enhancing performance.

\section{Theory}

Numerous theoretical treatments of MFCs can be found in the literature. Studies that highlight the importance of prestress [17] and its nonlinear aspects [18, 19] are particularly relevant. In addition, Classical Laminate Theory has been applied to MFCs [20]. Additionally, computer models have been developed [21,22].

For our flap design, the MFC was mounted to a metal substrate. The details are given in the experimental procedures section. A characteristic curvature is realized when an electrical field is applied to the actuator. The electric response displacement of these curved actuators can be expressed in a variety of ways, including tip displacement, dome height $h$ [23], or normalized dome height [24]. We represent the voltage response displacement in terms of curvature $\kappa=1 / R$, where $R$ is the radius of curvature. The curvature can be related to the dome height $h$ via (1) [25].

$$
h=d \sin \left(\frac{s \kappa}{2}\right)+R\left(1-\cos \left(\frac{s \kappa}{2}\right)\right) \text {. }
$$

Here, $s$ is the arc length of the piezoelectric patch and $d$ is the length of the tab on each end of the actuator. The tab is a portion of the substrate left uncovered by the piezoelectric patch on some actuator designs. The curvature $\kappa$ is zero for a flat actuator and increases for a more curved actuator. A negative $(-)$ curvature corresponds to curvature up and a positive $(+)$ curvature corresponds to curvature down. For example, simply hanging a mass on the end of the cantilevermounted actuator produces a positive $(+)$ curvature.

The tip displacements $y$ were obtained from the micrometer measurements described in the experimental procedures section. For a flat actuator, $y=0$. The distance $x$ is measured from the point on the actuator where the tip displacement measurements were made to the cantilever pivot point. Equation (2) relating $x$ and $y$ to the radius of curvature $R$ can be derived from simple geometry:

$$
R=\frac{x^{2}}{2 y}+\frac{y}{2}
$$

Other flap configurations include flaps with tabs of length $d$ extending well beyond the piezoelectric patch. In this case, the tip deflection angle $\sigma$ is given by

$$
\tan \sigma=\frac{R-R \cos (s / R)+d \sin (s / R)}{R \sin (s / R)+d \cos (s / R)} .
$$

If a mass load is applied to the actuator prior to applying the electric field, an initial curvature results. The situation can be treated analytically, by adapting a well-known mechanical engineering beam problem [26]. The piezoelectric actuator can be approximated as a passive column or simply supported horizontal beam of length $L$ with pinned ends. The piezoelectric force is represented as an external force $F$ acting inward on each end of the beam. Further, assume that the beam has an initial curved shape $v_{0}(z)$, where $z$ is the coordinate along the length of the beam. The applied point mass is not directly included in this analysis. It is indirectly incorporated by virtue of the fact that the initial shape is due to the applied point mass load.

The second order inhomogeneous differential equation that characterizes the shape $v(z)$ of the actuator is given by

$$
\frac{d^{2} v}{d x^{2}}+\frac{F}{E I} v=\frac{F}{E I} v_{0}
$$

Here $E$ is Young's modulus and $I$ is the area moment of inertia. Based on experimental results, the actual initial shape of the actuator is a circle segment. However, a closed form solution can easily be found if we approximate the initial actuator curvature by the following expression

$$
v_{0}(z)=a_{0} \sin \frac{\pi z}{L} .
$$

Here, $a_{0}$ is the initial displacement at the center of the actuator and is related to the radius of curvature by (1) with $a_{0}$ substituted for $h$. After applying the appropriate boundary conditions, the general solution is

$$
v(z)=\frac{1}{\left(F_{\mathrm{cr}} / F\right)-1} v_{0}(z) .
$$

Here $F_{c r}$ can be recognized as the critical load for an initially straight beam and is given by the following expression:

$$
F_{\mathrm{cr}}=\frac{E I \pi^{2}}{L^{2}} .
$$

The relevant point for our discussion can be seen in (6). For a given piezoelectric force $F$, subsequent deformations $v(z)$ are proportional to initial displacements $v_{0}(z)$.

\section{Experimental Details}

The initial approach for realizing control surfaces in morphing wings was to bond the MFC to metal substrates and then use them in a flap configuration as depicted in Figure 1. This configuration is similar to a conventional flap and provided large displacements under mass load conditions. Although similar to conventional flaps, one big advantage of the piezoelectric flap over the conventional flap, for inflatable wings, is that the piezoelectric flap is controlled by electrical leads rather than hydraulics or mechanical linkages.

For the flap measurements, two custom actuators were constructed by Smart Material Corporation. One actuator 
TABLE 1: MFC actuator substrates.

\begin{tabular}{lccc}
\hline Substrate & $\begin{array}{c}\text { Thickness } \\
\pm 0.005(\mathrm{~mm})\end{array}$ & $\begin{array}{c}\text { Width } \\
\pm 0.05(\mathrm{~mm})\end{array}$ & $\begin{array}{c}\text { Length } \\
\pm 0.05(\mathrm{~mm})\end{array}$ \\
\hline Steel & 0.381 & 43.90 & 105.19 \\
Aluminum & 0.368 & 44.31 & 109.60 \\
\hline
\end{tabular}

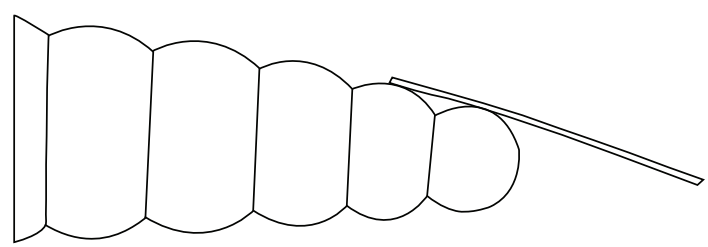

FIGURE 1: Conceptual illustration representing the cross-section of an inflatable wing with an attached flap-like actuator.

was constructed by bonding two MFC sheets, Smart Material Corporation model number M 8528 B3518 O1P1, to each side of a steel substrate. The other actuator was constructed in a similar manner with an aluminum substrate. The dimensions of the custom constructed actuator substrates are given in Table 1. The rationale for bonding MFC sheets to both the bottom and top was to create a push-pull effect. The push-pull effect is a result of applying the voltages to both actuators with opposite voltage polarities. One electrical lead combination and voltage polarity tended to produce a concave up curvature, whereas the opposite combination tended to produce concave down curvatures. The actuators were mounted in cantilever mode for experimental convenience. A custom mass hanger was affixed near the free end of the cantilever so load masses could be applied. The applied mass loads are intended to simulate aerodynamic drag forces on the flaps. Therefore, an upward tip actuation simulates the flaps acting against the drag forces and a downward tip actuation simulates the flaps acting with the drag forces.

The experimental arrangement is depicted in Figure 2. A low frequency $(2 \mathrm{~Hz})$ sinusoidal signal was produced by a function generator and then amplified by a Kepco BP 1000 high voltage amplifier. Care must be taken that the electrical power source is not only capable of supplying the required voltages, but it must also supply the peak currents to a very reactive, mostly capacitive, load. The applied peak-topeak voltage was independently monitored by both a digital oscilloscope, and by a DAQ card (National Instruments model PCI 6024E). The current output of the micrometer was applied to the current sensing resistor. The voltage across the resistor was monitored by a separate channel on the same DAQ card and was monitored independently by a separate channel of the digital oscilloscope. The DAQ inputs were buffered by a high impedance buffer circuit. The maximum resolution was limited by the 12-bit vertical resolution of the DAQ card to 5 micrometers.

The experimental data acquisition and control was accomplished with LabVIEW Virtual Instruments (VIs) interfacing software with both the GPIB and DAQ systems. LabVIEW VIs were written in-house and designed to collect the output from both the laser micrometer and the power

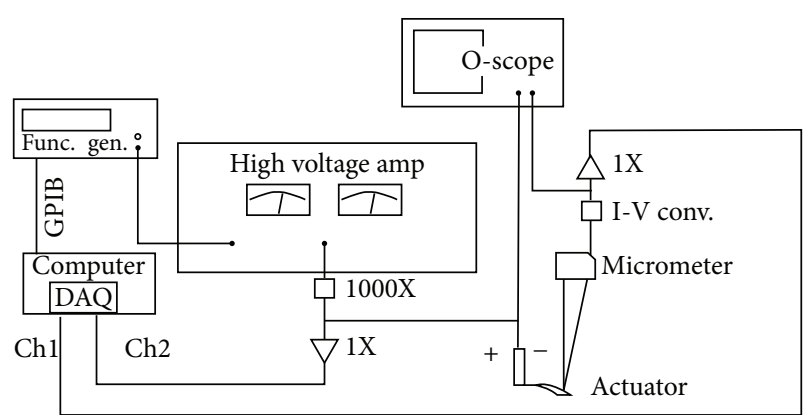

FIGURE 2: Experimental test set-up for the flap-like measurements.

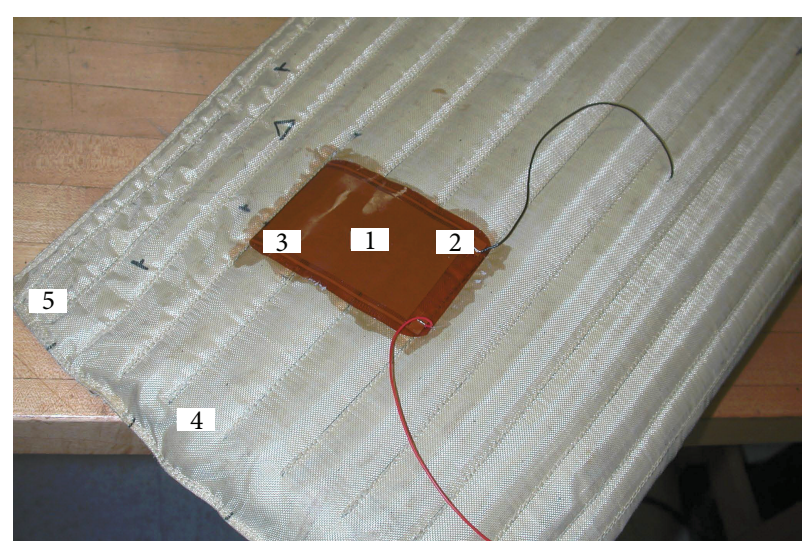

FIgURE 3: Photograph of MFC bonded to inflatable wing. The numbered locations correspond to where displacement data was obtained.

supply acquired from the DAQ. The VIs captured 512 data points over one complete cycle of the displacement and applied voltage. A full range of applied voltages was acquired for each load mass ranging from 9.1 grams to 309.1 grams \pm 0.1 gram. The minimum load represents the mass of the hanger. Measurements were repeated for increasing and decreasing masses and were repeated several times for each actuator substrate, aluminum, and steel. The measurements were very reproducible.

The displacement measurements were made in a noncontact manner with a Micro-Epsilon model 1400-5 laser micrometer. This micrometer has a measurement range of $5 \mathrm{~mm}$ and a resolution of 3 micrometers. The micrometer outputs a current in the range of $4-19 \mathrm{~mA}$ that is proportional to the displacement. The micrometer was calibrated and checked for linearity across the entire range against a computer automated Michelson interferometer. The interferometer was constructed in-house. At high mass loads an additional long range (20 centimeters), but lower resolution $(40 \mu \mathrm{m})$, micrometer (Micro-Epsilon model number 1400200) was used. The uncertainties of the displacement measurements were below $5 \%$ relative uncertainty.

For the direct bonding approach, the initial bonding tests were conducted on a small sample of Kevlar, the same Kevlar used in the construction of the airfoil. ILC Dover provided an inflatable airfoil for use in this project. See Figure 3. The airfoil 
is a 0018 symmetric design and has a maximum operating pressure of $69 \mathrm{kPa}(10 \mathrm{psi})$ relative pressure. The wing is $0.8133 \mathrm{~m}$ (32.02 inches) long and $0.4318 \mathrm{~m}$ (17.00 inches) wide at the root, tapering down to $0.2809 \mathrm{~m}$ (11.06 inches) at the tip. The wing is constructed from Kevlar fabric that is sewn into an airfoil shape with multiple spars running along its span. The spars provide structural support when the wing is inflated as well as maintaining well-defined volumes into which a polymeric bladder is inserted (similar to a hand being inserted into a glove) to act as the air retention mechanism. The root of the wing was attached to an aluminum mounting plate fitted with a gas inlet. More details about the wing can be obtained from $[15,16]$.

The actuator chosen for the direct bonding measurements was the MFC model 26E03-006B manufactured by Smart Material Corporation. The actuator dimensions are $74.2 \mathrm{~mm}$ $\times 98.7 \mathrm{~mm} \pm 0.2 \mathrm{~mm}$. A location near the outermost trailing edge of the wing, spanning the four wing spars closest to the trailing edge, not including the spar that constitutes the trailing edge itself, was identified as the location on the wing that could provide the greatest change in aerodynamic lift for given actuator displacements. Unfortunately, this location could not be utilized because three of the spars were inactive (i.e., not pressurized) due to knotting that occurred in the air bladder in the interior of the wing. The actuator was bonded to the wing as close to the trailing edge as possible while avoiding the knotted areas. The actuator then had to be moved slightly closer to the root of the wing so that the entire length of the actuator would span exactly three spars. The center of this location is $141 \pm 1 \mathrm{~mm}$ from the tip and $142 \pm$ $1 \mathrm{~mm}$ from the trailing edge. The adhesive used to bond the actuator to the airfoil was EP 31 developed by Master Bond Incorporated. This two-part epoxy has a $20 \mathrm{kN}(4500 \mathrm{lb})$ shear strength, which greatly reduces compliance problems that may limit the performance of the actuator/Kevlar system. Both the actuator and the airfoil (depressurized) were cleaned with acetone. The importance of cleaning the bonding surfaces cannot be overstressed. In preparation for bonding the actuator to the airfoil, the deflated airfoil was held in place and pressed flat. The adhesive was allowed to cure for 28 hours at room temperature before the airfoil was repressurized. Bonding reliability was tested by repeatedly applying sinusoidal voltage signals to the actuators over a range of frequencies from below one Hertz to above one kilohertz with amplitudes less than 1500 Volts peak to peak with a 500 Volt offset. At higher frequencies (higher ramp rates) the current demands on the high voltage amplifier becomes significant. The reason for the voltage asymmetry is due to the preferred direction produced during the initial piezoelectric poling preparation. Electric breakdown is the effective limit on voltages in the same direction as the poling direction. The limiting factor in the reverse direction is depoling. The applied voltages in this investigation were below $75 \%$ of the rated voltage capacity of the MFC actuator. The bond was visually inspected periodically with no evidence of bond degradation. After realizing successful bonding of the MFC to the wing, displacements were measured at various points shown in Figure 3. During measurements, the frequency of the applied voltage was one Hertz, which is well below any

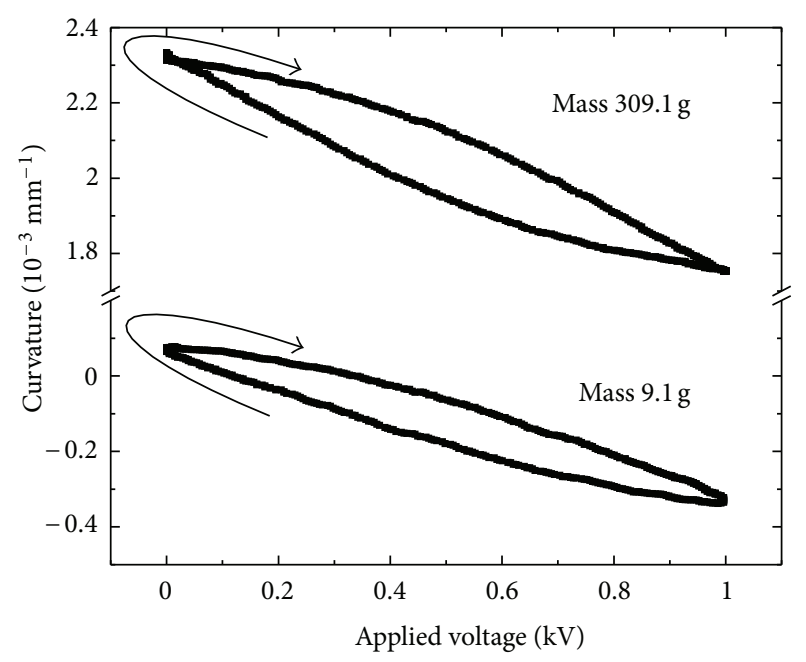

FIGURE 4: Two representative curves of curvature $(\kappa)$ versus applied voltage for two load masses. The lower curve shows actuation through the flat position $(\kappa=0)$. The leads were attached to produce actuation against the applied load.

electrical or mechanical resonances. Initial applications of the voltage indicated that the displacement was very small. Even small displacements may be useful for active boundary layer control techniques, thus an in-depth investigation of the displacements was conducted.

\section{Results and Discussion}

Figure 4 shows two representative data sets for the steel substrate acting against the applied load, upward. The arrows in the figure indicate the direction around the loop as a function of applied voltage. The lower curve is with the load of the mass hanger $(9.1 \mathrm{~g})$. The upper curve is with a total load of $309.1 \pm 0.1 \mathrm{~g}$. Focusing first on the low mass load curve, the actuator starts out with a slight downward $(+)$ curvature $(\kappa=$ $0.749 \times 10^{-4} \mathrm{~mm}^{-1}$ ) due to the mass at zero applied voltage. As the voltage is increased, the actuator becomes flat at $0.35 \mathrm{kV}$ then becomes curved upward (-) until at $1 \mathrm{kV}$ applied voltage the curvature is $-3.4 \pm 0.1 \times 10^{-3} \mathrm{~mm}^{-1}$. For the upper curve, (309.1 g) the actuator starts with a downward curve $(+)$ due to the mass and becomes less curved with applied voltage. Both curves show significant hysteresis, which is expected for piezoelectric devices, even for small applied electric fields well below those required to repole the piezoelectric ceramic. However, other sources of hysteresis such as mechanical losses should also be considered. A more detailed treatment of nonlinear responses of piezoelectric composite actuators can be found elsewhere $[18,27,28]$. If the actuator response is approximated to first order by a linear fit, a performance can be defined as curvature per applied voltage and can be read as the effective slope from the curvature versus applied voltage plots. The fact that the slopes are negative is an artifact of the sign convention chosen to define curvature up and down.

Figure 5 shows the magnitude of the performance as a function of mass load for several masses. The performance 


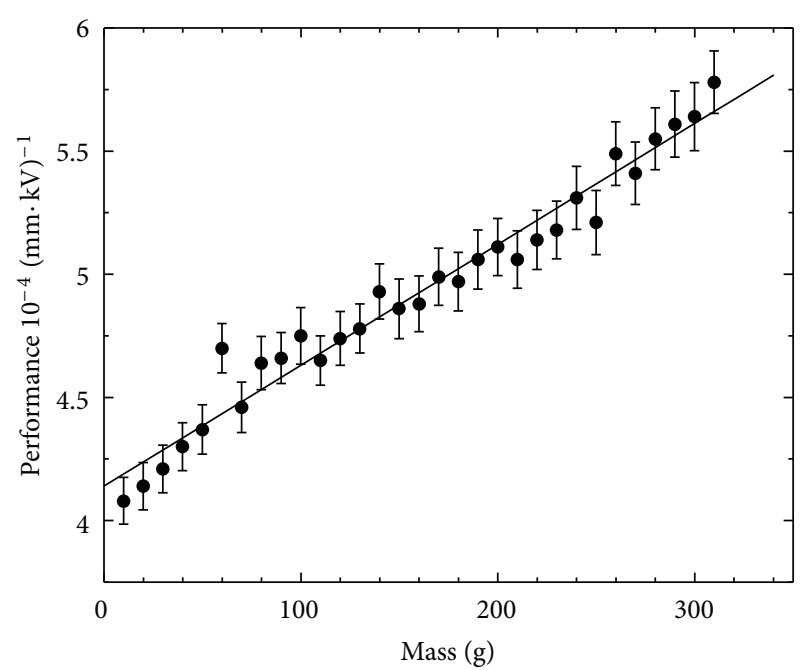

FIGURE 5: Actuation performance, as a function of load mass. Electrical leads were attached to produce actuation acting against the load mass.

increases linearly with increased load mass. The slope is $4.9 \pm$ $0.2 \times 10^{-7}(\mathrm{~mm} \cdot \mathrm{kV} \cdot \mathrm{g})^{-1}$. The actuator, in fact, produces a larger change in curvature with greater loads for a given applied voltage. At first glance, this may seem counter intuitive. However, larger mass loads produce larger initial curvatures that favor greater performance. This can be seen from (6).

There are competing effects here. Of course, the larger mass loads require more force to move. However, the mass loads also provide an initial curvature, which tends to enhance the performance. The result is a slight net increase of the performance. Figure 6 shows a family of curves for a variety of mass loads. The expected Hooke's law type behavior for zero applied voltages is evident. The aluminum substrate showed similar results. However, the performance was less predictable for the aluminum substrate. The magnitude of the performance increased linearly from an initial value of $1.14 \times 10^{-3}$ to a value of $1.30 \times 10^{-3}$ for a $150 \mathrm{~g}$ load. The performance, as a function of mass, increased up to $150 \mathrm{~g}$ and then decreased linearly back to the original value at $250 \mathrm{~g}$ and remained there until the maximum load of $300 \mathrm{~g}$. Furthermore, as seen in Figure 7 the hysteresis was also less predictable. Another interesting phenomenon was the looping at the end of the hysteresis curves near mass loads of $120 \mathrm{~g}$. This was evident in both aluminum and steel. However, it was more predominate for the aluminum substrate.

The flap approach produced significant displacements. It is interesting to ask how these results compare with traditional flaps. A straight comparison is not possible because, unlike traditional flaps that remain rigid, the piezoelectric flaps flex along their entire length. However, it is reasonable to compare the tangent angle of the piezoelectric near the tip. A simple geometric proof shows that the angle of the tip $\sigma$, in radians, relative to horizontal, is equal to the ratio of the actuator arc length $s$ to the radius of curvature $R(\sigma=$ $s / R=s \kappa)$. The arc length is equal to the length of the actuator

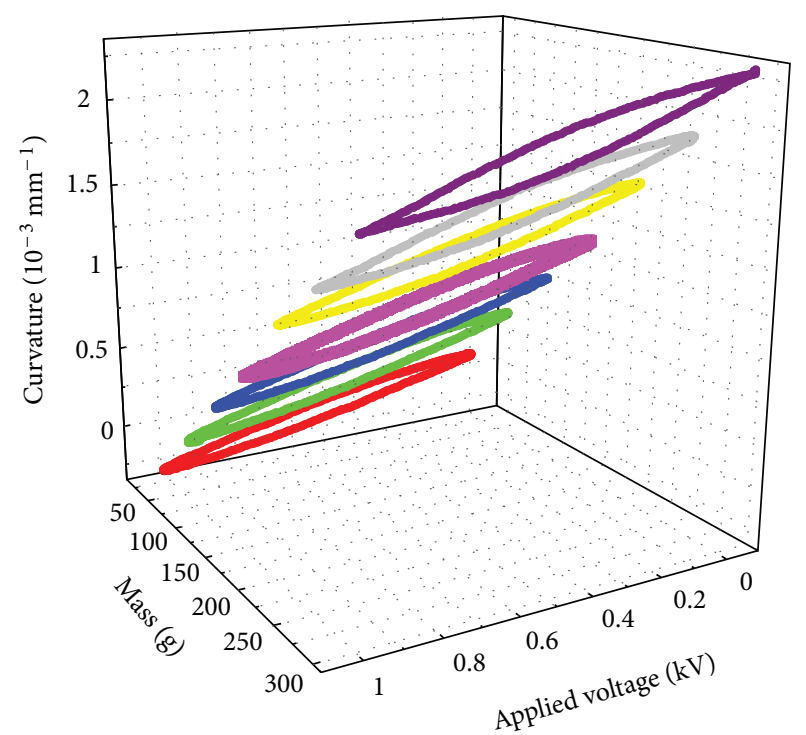

FIGURE 6: Curvature versus applied voltage for seven mass loads for a flap-like actuator with steel substrate. Electrical leads were attached to produce actuation acting against the load mass. Some data are omitted for clarity.

when flat. Using the dimensions of the steel substrate actuator $(s=105.2 \mathrm{~mm})$ and the change in curvature $\Delta \kappa=4.123 \times$ $10^{-4} \mathrm{~mm}^{-1}$ for a $9.1 \mathrm{~g}$ mass load and $1 \mathrm{kV}$ applied voltage we get a tip angle deflection of $2.48 \pm 0.05$ degrees which is small compared to traditional flaps. However, with optimization of parameters like the substrate thickness and length, larger angles should be obtainable. Other flap configurations include flaps with tabs of length $d$ extending beyond the piezoelectric patch. In this case, the tip deflection angle $\sigma$ given by (3) would be much greater.

For the direct bonding approach, baseline data on the depressurized wing $(0 \mathrm{psi})$ while laying flat was obtained. Voltage was applied and displacement measurements taken at 3 points on the actuator. For zero mechanical loads (tension), maximum displacements of $63 \pm 3 \mu \mathrm{m}$ were recorded. The next pressure measurement was at $34 \mathrm{kPa}(5 \mathrm{psi})$. The wing system would not sustain lower constant pressures. Measurements were made at the same three points as in the 0 psi test, plus two additional points on the wing located at the tip of the wing and at the tip of the trailing edge of the wing. The results are shown in Figure 8. Displacement data was also acquired at $48 \mathrm{kPa}$ (7 psi). At this pressure, the displacements were approaching the resolution of the micrometer at every point except test point 1 . Displacement measurements at pressures greater than $48 \mathrm{kPa}$ (7 psi) were below experimental uncertainty. Bonding reliability was tested by cycling the MFC through thousands of actuations over several days. The experimental measurements were duplicated several times with reproducible results.

Although the actuator did not bond completely to the seams of the wing, the majority of the area of the actuator (>90\%) formed a strong bond with the wing. In future work, it may be advantageous to raise the temperature of the bonding 


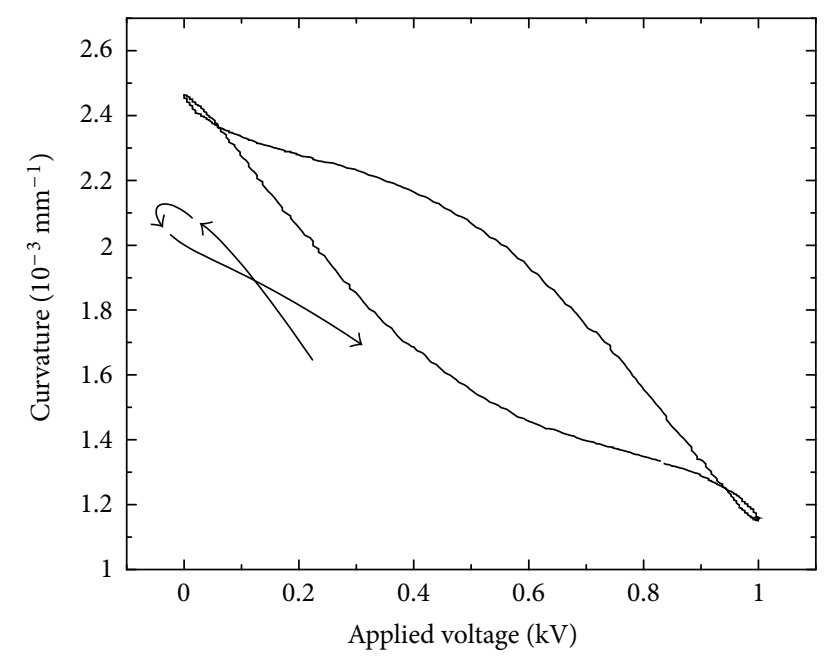

Figure 7: Curvature $(\kappa)$ versus applied voltage for a flap-like, aluminum substrate actuator. A looping phenomenon is evident near the extremes of the main hysteresis loop. The electrical connections are such as to produce displacement acting against the applied load of $120.1 \mathrm{~g}$.

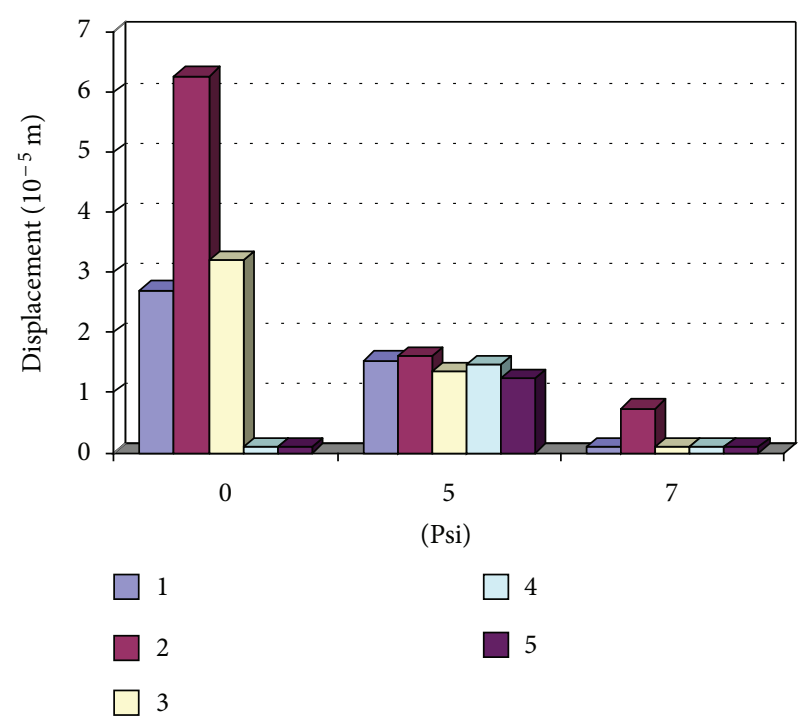

FIGURE 8: Wing displacement as a function of internal wing pressure. Locations 1 through 5 correspond to the different locations on the wing, illustrated in Figure 3.

area in order to achieve an even stronger bond with shorter curing times. Ideally, the actuators would be incorporated into the wing during construction of the wing, rather than retrofitting them.

The observed displacements at high pressures were small, resulting in only slight changes in the cross-sectional shape of the wing, thereby limiting the effect on flight characteristics of the airfoil during flight. However, the low pressure and fabric sample tests did produce appreciable displacements. The displacements were strongly dependent on pressure, indicating that the displacements are load (mechanical) limited by the fabric tension. One solution to this problem is to stack the actuators to increase the force generated and/or use larger actuators. In addition, the possibility of using the actuators to generate wing twist may prove useful. Another approach would be to alter the wing design to take specific advantage of the actuators. A portion of the outer trailing edge of the wing could be "removed" and replaced by an inflatable section hinged on a strip of Kevlar fabric. This would provide a free moving portion of the wing for use in altering lift. Without having to work against the tension in the fabric across the entire length of the wing, the actuator would then only have to work against aerodynamic forces. This could be accomplished without compromising the advantage of a small deployment volume.

\section{Conclusions}

Piezoelectric MFC sheets can be successfully incorporated into inflatable wings. Two approaches were explored. In one approach, MFC sheets were bonded to metal substrates and affixed to the trailing edge of the wing in a manner similar to traditional wing flaps. The voltage dependent displacements were characterized in terms of curvature $(\kappa)$. Mass loading the actuator produced a counter intuitive increase in the performance of the actuator. Flap tip angle deflections of $2.48 \pm 0.05$ degrees were obtained. In the other approach, MFCs were attached directly to the upper surface of the wing. At zero pressure, displacements as high as $63 \pm 3$ micrometers were obtained. As the pressure of the wing increased the displacements diminished toward zero within experimental uncertainty at a pressure of $48 \mathrm{kPa}(7 \mathrm{psi})$. The main advantage of the direct attachment method is that it better maintains the flexibility of the wing. However, problems of tension loading with increased wing pressure need to be addressed. The flap approach produces greater displacements although it diminishes the flexibility of the wing. This is not an insurmountable problem depending on the application. For example, the flaps could be segmented so that they can be folded with the wing when deflated. However, once the flexibility of the MFC sheet has been diminished by bonding it to a metal substrate other composite actuators such as THUNDER actuators should be considered. They may provide larger displacements and they have been considered for other aeronautical applications [29]. They are also slightly more mature and are more easily modeled with Finite Element Methods [30] even though FEM models for MFCs have been published [22]. These FEM models can be used to optimize performance and incorporate them into wing designs. Additionally, wind tunnel tests need to be performed to verify the models under dynamic conditions.

\section{Acknowledgments}

The contributions of Kurt Kloesel, NASA Dryden, and David Cadogan, Tim Smith, and Matt MacKusik of ILC Dover are gratefully acknowledged. Contributions from Jacob Salazar, Francisco Rodriguez, and Gevale Ashford from CSUSB are also acknowledged. The technical support of James Sheu and 
Jan Mack (CSUSB) is appreciated. The inflatable wings were supplied by ILC Dover and the MFC actuators were supplied by Smart Materials Corporation. This research was funded by NASA, Grant no. 0051-0078, and DoD, Grants F49620-02-10413, F49620-02-1-0412, and W911NF-05-1-0591.

\section{References}

[1] V. Giurgiutiu, "Recent advances in smart-material rotor control actuation," in Proceedings of the 41st AIAA/ASME/ ASCE/AHS/ASC Structures, Structural Dynamics, and Materials Conference and ExhibitAIAA/ASME/AHS Adaptive Structures Forum, pp. 237-247, AIAA, Atlanta, Ga, USA, April 2000, Paper \# AIAA 2000-1709.

[2] J. L. San Emeterio and A. Ramos, "Models for piezoelectric transducers used in broadband ultrasonic applications," in Piezoelectric Transducers and Applications, A. A. Vives, Ed., pp. 97-110, Springer, New York, NY, USA, 2nd edition, 2008.

[3] Y. Sugawara, K. Onitsuka, S. Yoshikawa, Q. C. Xu, R. E. Newnham, and K. Uchino, "Metal-ceramic composite actuators," Journal of the American Ceramic Society, vol. 75, no. 4, pp. 996-998, 1992.

[4] G. H. Haertling, "RAINBOW ceramics-a new type of ultrahigh-displacement actuator," American Ceramic Society Bulletin, vol. 73, no. 1, pp. 93-96, 1994.

[5] K. M. Mossi, G. V. Selby, and R. G. Bryant, "Thin-layer composite unimorph ferroelectric driver and sensor properties," Materials Letters, vol. 35, no. 1-2, pp. 39-49, 1998.

[6] K. J. Yoon, S. S. Shin, H. C. Park, and M. K. Kwak, "Development of lightweight THUNDER with fiber composite layers," in Smart Structures and Materials 2000: Active Materials: Behavior and Mechanics, vol. 3992 of Proceedings of SPIE, pp. 57-64, Newport Beach, Calif, USA, March 2000.

[7] K. G. Webber, D. P. Hopkinson, and C. S. Lynch, "Application of a classical lamination theory model to the design of piezoelectric composite unimorph actuators," Journal of Intelligent Material Systems and Structures, vol. 17, no. 1, pp. 29-34, 2006.

[8] W. K. Wilkie, R. G. Bryant, J. W. High, R. L. Fox, R. F. Hellbaum, A. Jalink Jr. et al., "Low-cost piezocomposite actuator for structural control applications," in Smart Structures and Materials 2000: Industrial and Commercial Applications of Smart Structures Technologies, vol. 3991 of Proceedings of SPIE, pp. 323-334, Newport Beach, Calif, USA, March 2000.

[9] J. A. Palmer, B. Dessent, J. F. Mulling et al., "The design and characterization of a novel piezoelectric transducer-based linear motor," IEEE/ASME Transactions on Mechatronics, vol. 9, no. 2, pp. 392-398, 2004.

[10] R. Ganguli, "Survey of recent developments in rotorcraft design optimization," Journal of Aircraft, vol. 41, no. 3, pp. 493-510, 2004.

[11] S. C. Galea, T. G. Ryall, D. A. Henderson, R. W. Moses, E. V. White, and D. G. Zimcik, "Next generation active buffet suppression system," in Proceedings of the AIAA International Air and Space Symposium and Exposition: The Next 100 Years, Dayton, Ohio, USA, July 2003, Paper \# AIAA-2003-2905.

[12] S. Barbarino, O. Bilgen, R. M. Ajaj, M. I. Friswell, and D. J. Inman, "A review of morphing aircraft," Journal of Intelligent Material Systems and Structures, vol. 22, no. 9, pp. 823-877, 2011.

[13] R. B. Williams, G. Park, D. J. Inman, and W. K. Wilkie, "An overview of composite actuators with piezoceramic fibers," in
Proceedings of the 20th International Modal Analysis Conference, vol. 4753, pp. 421-427, Los Angeles, Calif, USA, February 2002.

[14] W. K. Wilkie, J. High, and J. Bockman, "Reliability testing of NASA piezocomposite actuators," in Proceedings of the 8th International Conference on New Actuators (Actuator 2002), Bremen, Germany, June 2002.

[15] D. Cadogan, T. Smith, R. Lee, S. Scarborough, and D. Graziosi, "Inflatable and rigidizable wing components for unmanned aerial vehicles," in Proceedings of the 44th AIAA/ ASME/ASCE/AHS/ASC Structures, Structural Dynamics, and Materials Conference, pp. 3688-3695, Norfolk, Va, USA, April 2003, Paper \# AIAA 2003-1801.

[16] D. Cadogan, T. Smith, F. Uhelsky, and M. MacKusick, "Morphing inflatable wing development for compact package unmanned aerial vehicles," in Proceedings of the 45th AIAA/ASME/ASCE/AHS/ASC Structures, Structural Dynamics and Materials Conference, pp. 3205-3217, Palm Springs, Calif, USA, April 2004, Paper \# AIAA 2004-1807.

[17] R. W. Schwartz and M. Narayanan, "Development of high performance stress-biased actuators through the incorporation of mechanical pre-loads," Sensors and Actuators A, vol. 101, no. 3, pp. 322-331, 2002.

[18] X. Zhou and A. Chattopadhyay, "Nonlinear piezoelectric constitutive relationship and actuation for piezoelectric laminates," in Proceedings of the 43rd Structures, Structural Dynamics and Materials Conference, pp. 1903-1913, Denver, Colo, USA, April 2002, Paper \# AIAA 1438.

[19] R. B. Williams, Nonlinear mechanical and actuation characterization of piezoceramic fiber composites [Ph.D. thesis], Virginia Polytechnic Institute and State University, Blacksburg, Va, USA, 2004.

[20] R. B. Williams, B. W. Grimsley, D. J. Inman, and W. K. Wilkie, "Manufacturing and mechanics-based characterization of macro fiber composite actuators," in Proceedings of the ASME International Adaptive Structures and Materials Systems Symposium, New Orleans, La, USA, November 2002.

[21] M. S. Azzouz, C. Mei, J. S. Bevan, and R. J. Jong, "Finite element modeling of MFC/AFC actuators and performance of MFC," Journal of Intelligent Material Systems and Structures, vol. 12, no. 9, pp. 601-612, 2001.

[22] W. Beckert and W. S. Kreher, "Modelling piezoelectric modules with interdigitated electrode structures," Computational Materials Science, vol. 26, pp. 36-45, 2003.

[23] T. D. Usher, A. Sim, G. Ashford, G. Camargo, A. Cabanyog, and K. Ulibarri, "Modeling and applications of new piezoelectric actuator technologies," in Smart Structures and Materials 2004: Modeling, Signal Processing, and Control, vol. 5383 of Proceedings of SPIE, pp. 31-38, San Diego, Calif, USA, March 2004.

[24] J. Mulling, T. Usher, B. Dessent et al., "Load characterization of high displacement piezoelectric actuators with various end conditions," Sensors and Actuators A, vol. 94, no. 1-2, pp. 19-24, 2001.

[25] M. Capozzoli, J. Gopalakrishnan, K. Hogan et al., "Modeling aspects concerning THUNDER actuators," in Smart Structures and Materials: Mathematics and Control in Smart Structures, vol. 3667 of Proceedings of the SPIE, pp. 719-727, San Diego, Calif, USA, March 1999.

[26] A. C. Ugural and S. K. Fenster, Advanced Strength and Applied Elasticity, Prentice Hall, Upper Saddle River, NJ, USA, 4th edition, 2003. 
[27] T. Usher and A. Sim, "Nonlinear dynamics of piezoelectric high displacement actuators in cantilever mode," Journal of Applied Physics, vol. 98, no. 6, Article ID 064102, 7 pages, 2005.

[28] Y. Kim, L. Cai, T. Usher, and Q. Jiang, "Fabrication and characterization of THUNDER actuators-pre-stress-induced nonlinearity in the actuation response," Smart Materials and Structures, vol. 18, no. 9, Article ID 095033, 2009.

[29] J. L. Pinkerton and R. W. Moses, "A feasibility study to control airfoil shape using THUNDER," NASA Technical Manuscript TM-4767, 2003, http://ntrs.nasa.gov/archive/nasa/casi.ntrs .nasa.gov/19970041605_1997093204.pdf.

[30] C. Kennedy, T. Usher, J. Mulling, and A. Kingon, "Modeling and simulation of THUNDER actuators using ANSYS finite element analysis," in Proceedings of the International Conference on Modeling and Simulation of Microsystems (MSM'01), pp. 330-333, Nanotech 2001, Hilton Head Island, SC, USA, March 2001. 

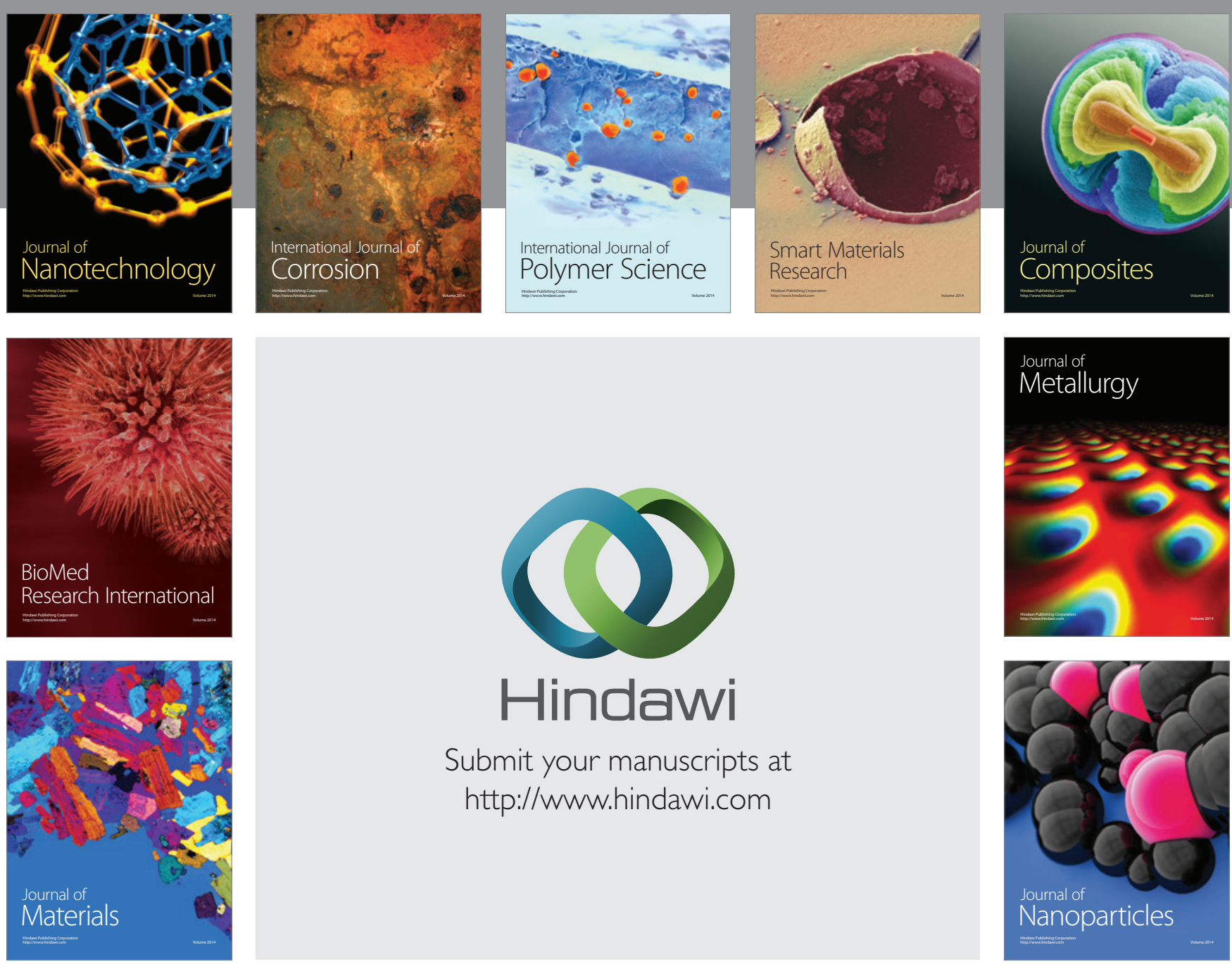

Submit your manuscripts at http://www.hindawi.com
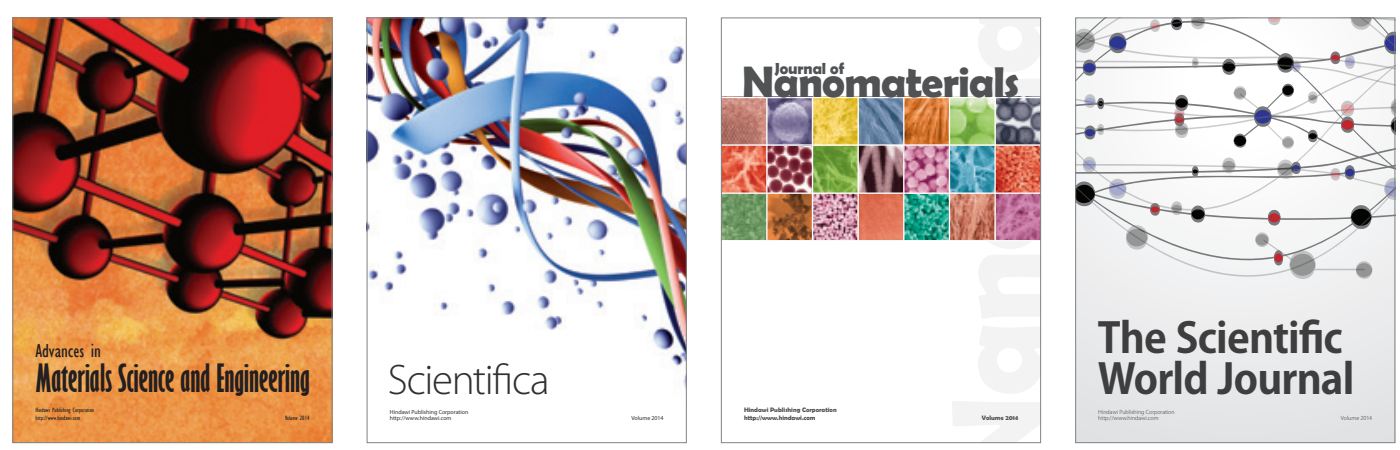

\section{The Scientific World Journal}
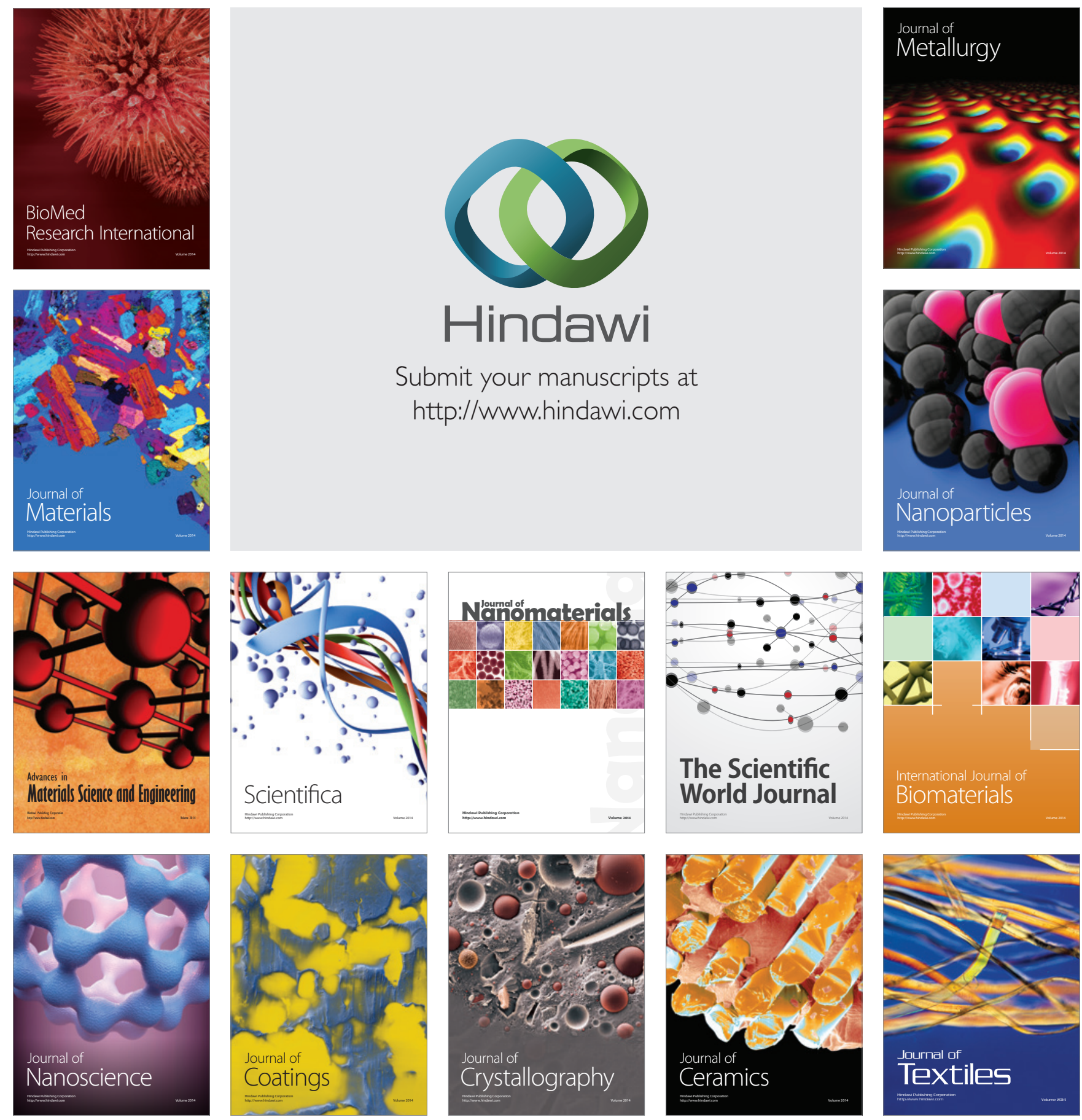